\title{
Correction to: Instant Gratification Behavior Among Gambling Individuals in Uganda
}

\author{
Rogers Matama ${ }^{1} \cdot$ Musa Mbago $^{1}$ (D) Pascal Ngoboka $^{2}$ \\ Published online: 17 October 2020 \\ (c) Springer Science+Business Media, LLC, part of Springer Nature 2020
}

\section{Correction to: Journal of Gambling Studies https://doi.org/10.1007/s10899-020-09973-y}

The original version of this article unfortunately contained a mistake. The corrected details are given below.

(a). Under heading "Discussions" the following sentence "For example, Uganda has the lowest monthly minimum wage in Sub-Saharan Africa, and its yearly minimum wage is $\$ 95,000$, and there are 121 countries with a higher minimum wage than Uganda which is at the bottom percentage of all countries (Minimum Wage Organization 2018)" should be corrected to "For example, Uganda has the lowest monthly minimum wage in Sub-Saharan Africa, and its yearly minimum wage is USD 95.00, and there are 121 countries with a higher minimum wage than Uganda which is at the bottom percentage of all countries (Minimum Wage Organization 2018)".

Publisher's Note Springer Nature remains neutral with regard to jurisdictional claims in published maps and institutional affiliations.

The original article can be found online at https://doi.org/10.1007/s10899-020-09973-y.

Musa Mbago

mmbago@mubs.ac.ug

1 Department of Procurement and Logistics Management, Makerere University Business School, Kampala, Uganda

2 Department of Economics, University of Wisconsin, Madison, USA 